\title{
Inhibition by 3-Deoxy-3-Fluoro-D-Glucose of the Utilization of Lactose and Other Carbon Sources by Escherichia coli
}

\author{
By R. J. MILES* AND S. J. PIRT \\ Department of Microbiology, Queen Elizabeth College, \\ Campden Hill Road, London, W. 8
}

(Received I 3 July I972; revised I 5 January I973)

SUMMARY

\begin{abstract}
3-Deoxy-3-fluoro-D-glucose (3FG) was converted to 3 FG-6-phosphate by the phosphoenolpyruvate-dependent phosphotransferase system in frozen and thawed Escherichia coli. Up to $0.03 \mathrm{~g} 3 \mathrm{FG}$ was taken up/g bacterial dry wt. Uptake of $3 \mathrm{FG}$ was not lethal, though $3 \mathrm{FG}$ at 0 . I to Io $\mathrm{mm}$ completely prevented or severely inhibited utilization of lactose, fructose, glycerol, succinate, acetate and pyruvate. It prevented lactose utilization by inhibition of the synthesis and activity of both $\beta$-galactosidase and galactoside permease. 3 FG-resistant mutants were isolated which were deficient in the Enzyme II of the phosphoenolpyruvatedependent phosphotransferase system specific for glucose and for 3 FG. Our findings support the view that the 'glucose effect' may depend upon glucose itself or a glucose derivative, rather than upon catabolic products.
\end{abstract}

\section{INTRODUCTION}

3-Deoxy-3-fluoro-D-glucose $(3 \mathrm{FG})$ is an unnatural glucose analogue which was first synthesized in 1966 (Buck, Foster, Hems \& Webber, 1966). Its metabolism and metabolic effects have been investigated in Saccharomyces cerevisiae (Brunt \& Taylor, I967; Miles \& Pirt, 1969; Woodward, Taylor \& Brunt, 1969, 1971; Miles, 1972) and in Pseudomonas fluorescens (White \& Taylor, 1970). No catabolic products of $3 \mathrm{FG}$ were demonstrated in these investigations, although $3 \mathrm{FG}$ was oxidized to 3-deoxy-3-fluoro-D-gluconic acid, and perhaps also to 3-deoxy-3-fluoro-2-keto-D-gluconic acid in Pseudomonas fluorescens. As a substrate for yeast hexokinase (Brunt \& Taylor, 1967) and glucose oxidase (Miles \& Pirt, I969) 3 FG was utilized at $3 \%$ and $0.3 \%$ respectively of the rates of glucose consumption.

We report here some effects of $3 \mathrm{FG}$ on Escherichia coli, by which $3 \mathrm{FG}$ appears not to be catabolized. However, while $3 \mathrm{FG}$ does not affect the utilization of glucose, it is a powerful inhibitor of the utilization of a wide range of other carbon sources, and the extent of inhibition is greater than that reported for other non-catabolizable glucose analogues. The inhibitory effect of ${ }_{3} \mathrm{FG}$ and the isolation of resistant mutants has been reported briefly (Miles \& Pirt, I972). 3FG has also been used by Kornberg \& Smith (1972) to isolate mutants deficient in the transport of glucose and glucose analogues.

* Present address: Department of Applied Biology, Chelsea College, Hortensia Road, London, SWIO OQX. 


\section{Chemicals}

\section{METHODS}

3FG was synthesized by Dr A. K. Palmer (Palmer, I97I) essentially according to the method of Foster, Hems \& Webber (I967). It was recrystallized from acetone to give a fine crystalline material, m.p. I 2 to I I $4{ }^{\circ} \mathrm{C}, \alpha_{\mathrm{D}}+57{ }^{\circ} \mathrm{C}\left(c\right.$, I $\mathrm{H}_{2} \mathrm{O}$ ) (found $\mathrm{C}, 39 \cdot 5 \%, \mathrm{H}, 6 \cdot \mathrm{I} \%$, $\mathrm{C}_{6} \mathrm{H}_{11} \mathrm{FO}_{5}$ requires $\mathrm{C}, 39.6 \%, \mathrm{H}, 6.05 \%$ ). Methyl-C ${ }^{14}-\beta$-D-thiogalactoside was obtained from Schwarz Bioresearch Inc. All other chemicals were from normal commercial sources.

\section{Organisms}

Escherichia coli $\mathrm{KI} 2$ and, where specifically stated, $E$. coli ML308, a mutant of $E$. coli $\mathrm{KI} 2$ which differs from the wild-type in being constitutive for $\beta$-galactosidase and galactoside permease synthesis, were maintained on a peptone yeast extract agar.

The following minimal medium, supplemented with the appropriate carbon source, was used (amounts in g/l): $\mathrm{NaH}_{2} \mathrm{PO}_{4} \cdot 2 \mathrm{H}_{2} \mathrm{O}, 7 \cdot 8 ; \mathrm{K}_{2} \mathrm{HPO}_{4}, 8 \cdot 4 ;\left(\mathrm{NH}_{4}\right)_{2} \mathrm{SO}_{4}, 2 \cdot 0 ; \mathrm{MgCl}_{2}, 0 \cdot \mathrm{I} 3$; $\mathrm{FeSO}_{4} .7 \mathrm{H}_{2} \mathrm{O}, 0.007 ; \mathrm{CaCO}_{3}, 0.003 ; \mathrm{MnCl}_{2} .4 \mathrm{H}_{2} \mathrm{O}, 0.00 \mathrm{I} ; \mathrm{ZnSO}_{4}, 0.0005 ; \mathrm{CuCl}_{2} .2 \mathrm{H}_{2} \mathrm{O}$, $0.0003 ; \mathrm{CoCl}_{2} .6 \mathrm{H}_{2} \mathrm{O}, 0.0002 ; \mathrm{H}_{3} \mathrm{BO}_{3}, 0.0001 ; \mathrm{Na}_{2} \mathrm{MoO}_{4} .2 \mathrm{H}_{2} \mathrm{O}, 0.0003$; final pH 7.0 . Glucose, fructose or lactose at $2 \mathrm{~g} / \mathrm{l}$ or glycerol, pyruvate, acetate or succinate at $3 \mathrm{~g} / \mathrm{l}$ was used as carbon source. Acetate, pyruvate and succinate were added as their sodium salts. All carbon sources and 3 FG were sterilized by membrane filtration. For the isolation of mutant organisms the medium was solidified with agar.

In liquid culture, Escherichia coli was incubated at $37^{\circ} \mathrm{C}$ in flasks containing not more than I/IO of their volume of culture medium on rotary shakers with $25 \mathrm{~mm}$ throw at 220 rev./min. In growth experiments, $250 \mathrm{ml}$ flasks with $\mathrm{I} 3 \mathrm{~mm}$ diam. side arm tubes were used, and growth was determined by measuring the opacity of the culture in the side arm of the flask, using an EEL colorimeter. Opacity was linearly related to dry wt of bacteria over the range of culture densities studied.

Cell-free extracts were obtained by subjecting bacterial suspensions at $0{ }^{\circ} \mathrm{C}$ to four $30-\mathrm{s}$ periods of ultrasonic disintegration, using a I00-watt MSE ultrasonic disintegrator operating at maximum output.

\section{Assay procedures}

3FG. 3FG was assayed by the phenol-sulphuric acid method (Dubois, Gilles, Hamilton, Rebers \& Smith, 1956) or by a modification of the glucose oxidase method for glucose, described by Hugget \& Nixon (1957). In common with many other glucose analogues (Pazur, 1966), 3FG is a substrate for glucose oxidase, but is oxidized at a much lower rate. Samples ( $\mathrm{I} \mathrm{ml}$ ) of solutions to be assayed for $3 \mathrm{FG}$ were incubated at $35^{\circ} \mathrm{C}$ with $4 \mathrm{ml}$ of an enzyme-dye reagent consisting of glucose oxidase $(\mathrm{I} \cdot 2 \mathrm{~g} / \mathrm{l})$, peroxidase $(0.05 \mathrm{~g} / \mathrm{l})$ and $\mathrm{I} \%$ $(\mathrm{w} / \mathrm{v})$ dianisidine in ethanol $(5 \mathrm{ml} / \mathrm{l})$ made up in $0.5 \mathrm{M}$-sodium dihydrogen phosphate adjusted to $\mathrm{pH} 7.0$ with sodium hydroxide. The rate of oxidation of the chromogen dianisidine, measured as increase in absorbance at $420 \mathrm{~nm}$, was directly proportional to $3 \mathrm{FG}$ concentration up to $0.05 \mathrm{M}$. The assay was limited at low concentrations (below I.0 mM) by the instability of the oxidized chromogen over the time period required for the assay.

$\beta$-Galactosidase. $\beta$-Galactosidase activity in whole organisms was determined as $o$ nitrophenyl galactoside (ONPG) hydrolysis (Lederberg, 1950). Organisms were washed and then incubated in $0.05 \mathrm{M}$-sodium phosphate buffer, $\mathrm{pH} 6.5$, containing $2 \%(\mathrm{v} / \mathrm{v})$ toluene and $50 \mu \mathrm{g}$ chloramphenicol $/ \mathrm{ml}$ for $30 \mathrm{~min}$ at $37^{\circ} \mathrm{C}$. A $0.5 \mathrm{ml}$ sample of toluene-treated organisms was incubated at $37^{\circ} \mathrm{C}$ with $4.5 \mathrm{ml}$ of $\mathrm{I} .7 \mathrm{mM}$-ONPG in $0.05 \mathrm{M}$-sodium phosphate 
buffer, pH 6.5. After a suitable period (up to $20 \mathrm{~min}$ ) the reaction was stopped with $2 \mathrm{ml}$ of $\mathrm{I} \cdot \mathrm{O} \mathrm{M}-\mathrm{K}_{2} \mathrm{CO}_{3}$ and $o$-nitrophenol determined as increase in absorbance at $420 \mathrm{~nm}$. The $\beta$-galactosidase activity of cell-free extracts was similarly determined by incubation with ONPG in sodium phosphate buffer.

\section{Intracellular radioactivity}

A Millipore membrane filter (pore size $0.45 \mu \mathrm{m}$ ) was cooled with mineral salts medium at $0^{\circ} \mathrm{C}$. A suspension of radioactively labelled organisms was pipetted on to its centre, and quickly washed with $2 \times 5 \mathrm{ml}$ of mineral medium at $0^{\circ} \mathrm{C}$. The membrane was then transferred to a scintillation vial, and, after drying over phosphorus pentoxide for $24 \mathrm{~h}$, Io $\mathrm{ml}$ of $0.5 \% 2$-(4'-t-butylphenyl)-5-(4'-biphenyl)-I,3,4-oxadiazole (butyl-PBD) in toluene was added and the radioactivity assayed using a Phillips liquid scintillation spectrometer. Counts were corrected for efficiency (approximately $70 \%$ ) by the channel ratio method. Intracellular concentrations of methyl- $\mathrm{C}^{14}-\beta$-D-thiogalactoside were calculated using the internal cell volume $(2.7 \mathrm{ml} / \mathrm{g}$ dry $\mathrm{wt})$ determined by Winkler \& Wilson (I966).

\section{$o$-Nitrophenylgalactoside transport rate}

The rate of hydrolysis of ONPG by intact organisms is proportional to the transport rate of ONPG (Rickenberg, Cohen, Buttin \& Monod, I956). Organisms washed and resuspended in $0.05 \mathrm{M}$-sodium phosphate buffer, $\mathrm{pH} 7.0$, were incubated at $37^{\circ} \mathrm{C}$ with $\mathrm{I} \cdot 6 \mathrm{mM}$-ONPG. After a suitable incubation period, $\mathrm{K}_{2} \mathrm{CO}_{3}$ was added to $0.7 \mathrm{M}$, and $o$-nitrophenol was determined as increase in absorbance at $420 \mathrm{~nm}$.

\section{Phosphorylation of $3 F G$}

A $2 \mathrm{ml}$ portion of a suspension of organisms or of an extract was added to $0.5 \mathrm{ml}$ of $0.12 \mathrm{M}-\mathrm{MgCl}_{2}$ containing $3 \mathrm{FG}$ and other substrates where indicated. After up to $3 \mathrm{~h}$ at $37^{\circ} \mathrm{C}$, organisms were centrifuged off. $3 \mathrm{FG}$-phosphate in the supernatant was demonstrated qualitatively by ascending paper chromatography, using a butanol-ethanol-water solvent (100:60:36, by vol.) and developing with $p$-anisidine hydrochloride (Hough \& Jones, 1962). 3 FG-phosphate was determined quantitatively by removal of 3 FG-phosphate and subsequent assay of residual $3 \mathrm{FG}$ using the phenol-sulphuric acid method. 3 FG-phosphate was removed by ion exchange: $0.5 \mathrm{ml}$ samples were added to $9.5 \mathrm{ml}$ of distilled water and $5 \mathrm{~g}$ of Amberlite IR-45 (OH) in a boiling tube and the mixture was shaken for $45 \mathrm{~min}$ at room temperature. Paper chromatography showed that removal of $3 \mathrm{FG}-$ phosphate was virtually complete after this time.

\section{Uptake and phosphorylation of $3 F G$}

\section{RESULTS}

The initial step in the utilization of glucose by Escherichia coli is its transport into the organism and its phosphorylation by the phosphoenolpyruvate phosphotransferase system originally described by Kundig, Ghosh \& Roseman (1964). The ability of this system to phosphorylate $3 \mathrm{FG}$ was investigated in frozen and thawed bacteria which catalyse the phosphorylation of sugars in the extracellular medium in the presence of phosphoenolpyruvate (Ghosh \& Ghosh, 1968).

Paper chromatography using butanol-ethanol-water showed that, in the presence of phosphoenolpyruvate, $3 \mathrm{FG}\left(R_{F} 0.45\right)$ was converted to a compound with $R_{E} 0.05$, and this new compound was identified as 3 FG-6-phosphate by chromatographic comparison with chemically synthesized 3FG-6-phosphate (Palmer, I97I) in a number of solvent systems.

In the absence of externally added phosphoenolpyruvate, $3 \mathrm{FG}$ was phosphorylated at a 


\section{Table I. Rates of phosphorylation of $3 F G$ and 2-deoxyglucose}

Escherichia coli was harvested whilst growing exponentially in glucose medium, washed and resuspended in $0.05 \mathrm{M}$-sodium phosphate buffer, $\mathrm{pH} 7.0$ (bacterial dry wt $8.6 \mathrm{mg} / \mathrm{ml}$ ). Where indicated this suspension was used for the preparation of a cell-free extract, or was frozen at $-20^{\circ} \mathrm{C}$ for $14 \mathrm{~h}$. Initial concentrations of $3 \mathrm{FG}, 2$-deoxyglucose (2DG), phosphoenolpyruvate (PEP) and ATP were Io $\mathrm{mM}$.

$\begin{array}{llc} & & \begin{array}{r}\text { Rate } \\ \text { phosphory } \\ (\mu \text { moles }\end{array} \\ \text { Frozen and thawed bacteria } & \begin{array}{r}\text { Substrates } \\ \text { bacterial pr:PEP }\end{array} & \text { 3.I } \\ & \text { 3FG:ATP } & 0.08 \\ & \text { 3FG } & 0.03 \\ \text { 2DG:PEP } & 0.08 \\ \text { Fresh bacteria } & \text { 2DG:ATP } & - \\ \text { Cell-free extract } & \text { 3FG:PEP } & - \\ & \text { 3FG:PEP } & - \\ & \text { 3FG:ATP } & <0.02\end{array}$

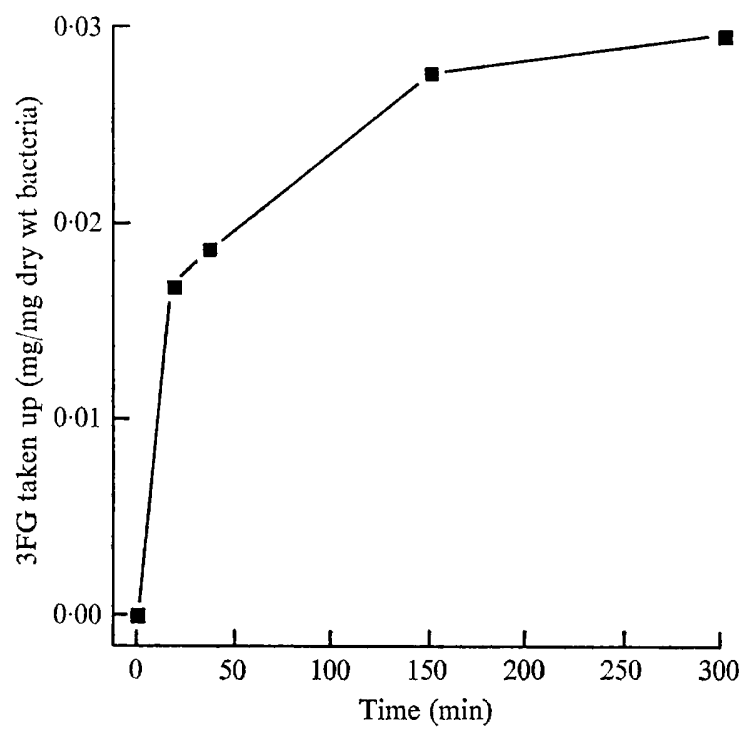

Fig. I. Uptake of ${ }_{3}$ FG by resting Escherichia coli. Washed overnight glucose-grown organisms suspended in minimal medium at $6 \mathrm{mg}$ dry bacterial $\mathrm{wt} / \mathrm{ml}$ were incubated at $37^{\circ} \mathrm{C}$ with $\mathrm{I} \mathrm{mg}$ $3 \mathrm{FG} / \mathrm{ml}$. At intervals samples were withdrawn, the bacteria removed by filtration and residual 3FG determined by the glucose oxidase method.

low rate, and this low rate was stimulated to a small extent by ATP (Table I). The origin of the 3 FG-6-phosphate formed under such circumstances is not certain. It may be due to the presence of small amounts of phosphoenolpyruvate within the organisms, and to stimulation of phosphoenolpyruvate synthesis by ATP; alternatively it may be due to hexokinase activity. Phosphorylation of 3 FG by cell-free extracts in the presence of ATP but not of phosphoenolpyruvate was demonstrated chromatographically; so $3 \mathrm{FG}$ is evidently a substrate for Escherichia coli hexokinase. However, hexokinase activity would appear of little consequence, since the rate of ATP-stimulated phosphorylation of ${ }_{3} \mathrm{FG}$, whether by frozen 
Table 2. The effect of adding $3 F G$ to cultures of Escherichia coli growing exponentially with various carbon sources

\begin{tabular}{lllc} 
& \multicolumn{3}{c}{ Final 3 FG concentration } \\
\cline { 2 - 4 } Carbon source & IO mM & $\mathrm{I} \cdot 0 \mathrm{mM}$ & $\mathrm{O} \cdot \mathrm{I} \mathrm{mM}$ \\
Glucose & + & + & + \\
Lactose & $\mathrm{R}(\mathrm{I})$ & $\mathrm{R}(2)$ & + \\
Fructose & $\mathrm{R}(<\mathrm{I})$ & $\mathrm{R}(2)$ & + \\
Glycerol & $\mathrm{R}(<\mathrm{I})$ & $\mathrm{R}(<\mathrm{I})$ & $+(40 \%)$ \\
Pyruvate & $+(45 \%)$ & $+(65 \%)$ & $+(92 \%)$ \\
Acetate & $\mathrm{R}(<\mathrm{I})$ & $+(40 \%)$ & $+(55 \%)$ \\
Succinate & $\mathrm{R}(2)$ & $\mathrm{R}(3)$ & $+(84 \%)$
\end{tabular}

+ , Normal growth; +() , growth at lowered growth rate. Percentage of control growth rate in the absence of $3 \mathrm{FG}$ in brackets; R (), gradual decline in growth rate to zero. Number of generations before cessation of growth in brackets.

and thawed organisms or by cell-free extracts, was less than $2 \%$ of the rate of phosphoenolpyruvate-stimulated phosphorylation of $3 \mathrm{FG}$ by frozen and thawed organisms.

$3 \mathrm{FG}$ is a better substrate than 2-deoxyglucose for the phosphoenolpyruvate phosphotransferase system (Table I) and its observed rate of phosphorylation and presumably transport would be high enough to allow a substantial growth rate upon $3 \mathrm{FG}$, if $3 \mathrm{FG}$ were a carbon source for Escherichia coli. Yet when glucose-grown organisms were inoculated into $3 \mathrm{FG}$ medium, no growth occurred. After $5 \mathrm{~h}$ of incubation disappearance of $3 \mathrm{FG}$ from the medium had virtually ceased and uptake of ${ }_{3} \mathrm{FG}$ was limited to $0.03 \mathrm{~g} / \mathrm{g}$ dry wt of bacteria (Fig. I). The uptake of this small amount of ${ }_{3} \mathrm{FG}$ was not lethal since, even after prolonged pre-incubation with $3 \mathrm{FG}, E$. coli grew normally upon the addition of glucose. It appears that, as with Saccharomyces cerevisiae, ${ }_{3} \mathrm{FG}$ is not readily catabolized by $E$. coli.

\section{Effect of $3 F G$ on the utilization of various carbon sources}

Ten mM-3FG had no effect on the lag, growth rate or yield of Escherichia coli in glucose medium, though it increased the lag of glucose-grown organisms in media containing other carbon sources by more than 20 generation times. The concentrations of $3 \mathrm{FG}$ required to affect the lag with the various carbon sources used were: glycerol and lactose, o. I mM; succinate, fructose and pyruvate, $\mathrm{I} \mathrm{mM}$; and acetate $\mathrm{Io} \mathrm{mM}$. Where $3 \mathrm{FG}$ increased the lag by more than 20 generation times, growth, when it eventually occurred, was at a rate and final yield which approached those in the absence of ${ }_{3} \mathrm{FG}$. Such late growth, however, did not represent adaptation of the population as a whole; it was due to resistant mutants initially present in the population at a low frequency (see below).

In addition to preventing the growth of glucose-grown bacteria with carbon sources other than glucose, $3 \mathrm{FG}$ inhibited the growth of bacteria growing exponentially with, and therefore adapted to, these carbon sources. The form of inhibition (see Table 2) varied from a reduction in growth rate to complete cessation of growth within one to three generations after the addition of $3 \mathrm{FG}$.

Two hypotheses may be formulated for the mechanism of inhibitory action of ${ }_{3} \mathrm{FG}$ on the utilization of carbon sources other than glucose: either (I) that $3 \mathrm{FG}$ inhibits early steps in metabolism which are not involved in glucose metabolism; or (2) $3 \mathrm{FG}$ inhibits a step in metabolism required for growth on all carbon sources but it fails to affect glucose utilization because it competes poorly with glucose for transport into the organisms and for subsequent metabolism. 
The second hypothesis was tested by pre-incubating fresh glucose-grown organisms with Io mM-3FG in mineral medium under normal growth conditions and then adding glucose. Under these conditions any transport and metabolism of $3 \mathrm{FG}$ would not be competitively blocked by glucose, so any inhibitory effect should become apparent. However, after $24 \mathrm{~h}$ of incubation with $3 \mathrm{FG}$ the organisms grew at a normal rate and with a lag of less than $\mathrm{I} h$ after the addition of glucose. To confirm this finding $3 \mathrm{FG}$ was added (final concentration Io $\mathrm{mm}$ ) to organisms growing exponentially in lactose medium and after the growth rate had slowed by approximately $90 \%$, glucose was added. Growth at the normal glucose supported rate started within $30 \mathrm{~min}$, showing that the block in lactose utilization was no impediment to glucose utilization. These findings are not compatible with hypothesis (2).

\section{The mechanism of $3 F G$ inhibition of lactose utilization}

The early steps of lactose utilization which $3 \mathrm{FG}$ may inhibit are: (i) synthesis of $\beta$ galactosidase and galactoside permease; (ii) transport of lactose into the cell; (iii) hydrolysis of lactose by $\beta$-galactosidase. The effect of ${ }_{3} \mathrm{FG}$ on each of these steps was investigated.

\section{Effect of $3 F G$ on the synthesis of $\beta$-galactosidase and galactoside permease}

A high concentration (I mM) of isopropyl- $\beta$-D-thiogalactoside (IPTG) was used as inducer to avoid possible effects on enzyme and permease synthesis due to inhibition of inducer uptake by ${ }_{3} \mathrm{FG}$ (Cohn \& Horibata, I959). Since $\beta$-galactosidase and galactoside permease are always jointly synthesized in a fixed ratio of activities (Jacob \& Monod, I96I) only synthesis of $\beta$-galactosidase was followed.

When inducer and ${ }_{3} \mathrm{FG}$ at $0 \cdot \mathrm{I}$ to $10 \mathrm{~mm}$ were added to organisms growing in succinate medium, 3 FG caused a 65 to $85 \%$ reduction in $\beta$-galactosidase synthesis during the first $30 \mathrm{~min}$. After $40 \mathrm{~min}$ the rate of $\beta$-galactosidase synthesis in the presence of $3 \mathrm{FG}$ increased, and repression by $0 \cdot \mathrm{I}$ mM-3FG was overcome. At higher concentrations of $3 \mathrm{FG}$ repression was still apparent. It is evident that $3 \mathrm{FG}$ can cause a transient repression of $\beta$-galactosidase synthesis, but whether it can cause a permanent repression at $\mathrm{I} .0 \mathrm{~mm}$ and above is more difficult to ascertain. While the addition of ${ }_{3} \mathrm{FG}$ at such concentrations to bacteria growing with succinate did not affect growth during the first $30 \mathrm{~min}$, a significant decrease in growth rate was apparent within one generation time, and growth ceased within two generations. When growth is affected in this manner it is difficult to distinguish permanent from transient repression of synthesis of the gratuitious $\beta$-galactosidase.

Pyruvate and acetate were the only carbon sources other than glucose which were used in the presence of $\mathrm{I} \mathrm{mM-3} F \mathrm{FG}$, and even with these carbon sources the growth rate was lowered (see Table 2). The effect of ${ }_{3} F G$ on the differential rate of $\beta$-galactosidase synthesis in organisms growing with pyruvate and induced with IPTG was, however, determined. In the presence of $0.1 \mathrm{mM}-3 \mathrm{FG}$, the differential rate of $\beta$-galactosidase synthesis measured over several generations was not affected, though at I.0 mM-3FG it was lowered by $40 \%$. Further indirect evidence that $3 \mathrm{FG}$ may cause a permanent repression of $\beta$-galactosidase synthesis is presented later.

The effect of $3 \mathrm{FG}$ on $\beta$-galactosidase synthesis during the first $30 \mathrm{~min}$ after induction of bacteria growing in succinate medium with IPTG was completely reversed by the addition of 2 to 5 mM-cyclic $3^{\prime}, 5^{\prime}$-adenosine monophosphate (cyclic AMP). The mechanism of the repressive effect of $3 \mathrm{FG}$ on $\beta$-galactosidase synthesis would therefore appear to be the same as that reported for glucose and other glucose analogues (Perlman, Crombrugghe \& Pastan, 1969). 
Table 3. Efflux rate of TMG from Escherichia coli with and without $3 F G$

\begin{abstract}
Organisms growing exponentially in lactose medium were collected on a membrane filter, washed and resuspended (I $\mathrm{mg}$ dry $\mathrm{wt} / \mathrm{ml}$ ) in mineral medium containing $50 \mu \mathrm{g}$ chloramphenicol $/ \mathrm{ml}$. A $6 \mathrm{ml}$ sample of suspension was added to $1.5 \mathrm{ml}$ of $2.5 \mathrm{~mm}$-labelled TMG of specific radioactivity $20 \mu \mathrm{Ci} / \mathrm{mg}$ and shaken at $23{ }^{\circ} \mathrm{C}$ for $30 \mathrm{~min}$. A $2 \mathrm{ml}$ sample of such suspension was filtered through an ice-cooled membrane filter and the organisms were washed with mineral medium at $0^{\circ} \mathrm{C}$. They were then taken up in mineral medium $(24 \mathrm{ml})$ at $23{ }^{\circ} \mathrm{C}$, containing $3 \mathrm{FG}$ where appropriate. Duplicate $5 \mathrm{ml}$ samples, taken immediately and after shaking for $90 \mathrm{~s}$, were assayed for intracellular radioactivity. The result of three independent experiments are recorded.
\end{abstract}

\begin{tabular}{|c|c|c|}
\hline \multicolumn{2}{|c|}{$\begin{array}{l}\text { Reciprocal half efflux } \\
\text { time }\left(\mathrm{min}^{-1}\right)\end{array}$} & \multirow{2}{*}{$\begin{array}{c}\text { Decrease in efflux } \\
\text { rate with } 3 \mathrm{FG} \\
(\%)\end{array}$} \\
\hline No ${ }_{3} \mathrm{FG}$ & I $\mathrm{mm}-3 \mathrm{FG}$ & \\
\hline$I \cdot 43$ & $1 \cdot 14$ & $20 \cdot 2$ \\
\hline 1.56 & I 23 & $2 I \cdot 3$ \\
\hline $\mathrm{I} \cdot 35$ & $\mathrm{I} \cdot 03$ & $23 \cdot 8$ \\
\hline
\end{tabular}

\title{
Effect of $3 F G$ on the transport of galactosides
}

The effect of $3 \mathrm{FG}$ on galactoside transport in lactose-grown organisms was determined by measuring the uptake of methyl-C ${ }^{14}-\beta$-D-thiogalactoside (TMG). Washed lactose-grown organisms $\left(0.8 \mathrm{~g}\right.$ dry wt/l) were incubated at $23{ }^{\circ} \mathrm{C}$ in mineral medium containing $50 \mu \mathrm{g}$ chloramphenicol $/ \mathrm{ml}$, $0.5 \mathrm{mM}$-labelled TMG of specific activity $20 \mu \mathrm{Ci} / \mathrm{mg}$, and $3 \mathrm{FG}$ where appropriate. The intracellular concentration of TMG was determined between 2 and 60 min. In control suspensions the equilibrium intracellular concentration exceeded that in the medium by a factor of 12 ; $0 \cdot 1$ to Io $\mathrm{mM}-3 \mathrm{FG}$ lowered the equilibrium intracellular concentration by 60 to $70 \%$. This decrease represented inhibition of influx of TMG, rather than acceleration of efflux, since the efflux rate was inhibited by 3 FG (see Table 3).

The ability of ${ }_{3} \mathrm{FG}$ to inhibit galactoside influx into lactose-grown organisms was confirmed by determining its effect on hydrolysis of ONPG in vivo. $3 \mathrm{FG}$ at $0 \cdot \mathrm{I} \mathrm{mM}$ and above lowered the rate of ONPG hydrolysis in vivo by $80 \%$. However, the validity of the result may be questioned, as ONPG hydrolysis in vivo depends upon $\beta$-galactosidase activity and ${ }_{3} \mathrm{FG}$ inhibits $\beta$-galactosidase.

\section{Effect of $3 F G$ on $\beta$-galactosidase activity}

The inhibition of $\beta$-galactosidase activity by $3 \mathrm{FG}$ and by glucose are compared in Table 4: 3 FG was a far more effective inhibitor than glucose. The inhibitory effect of glucose has previously been reported though not characterized (Lederberg, 1950). The inhibition produced by $3 \mathrm{FG}$ is 'uncompetitive' (Dixon \& Webb, 1964); appropriate double reciprocal plots at different $3 \mathrm{FG}$ concentrations yielding a series of parallel lines (see Fig. 2).

Contribution of the inhibitory action of $3 F G$ on individual steps in lactose utilization to $3 F G$ inhibition of growth on lactose

3FG may severely inhibit both the activity and the synthesis of $\beta$-galactosidase and galactoside permease, and inhibition of these processes results in the inability of Escherichia coli to utilize lactose in the presence of ${ }_{3} F G$. The significance of inhibition of $\beta$-galactosidase and galactoside permease synthesis in preventing growth with lactose was determined using cyclic AMP and IPTG. Cyclic AMP should overcome repression of enzyme synthesis in the presence of inducer, and IPTG should overcome any repression due to lowering of intra- 


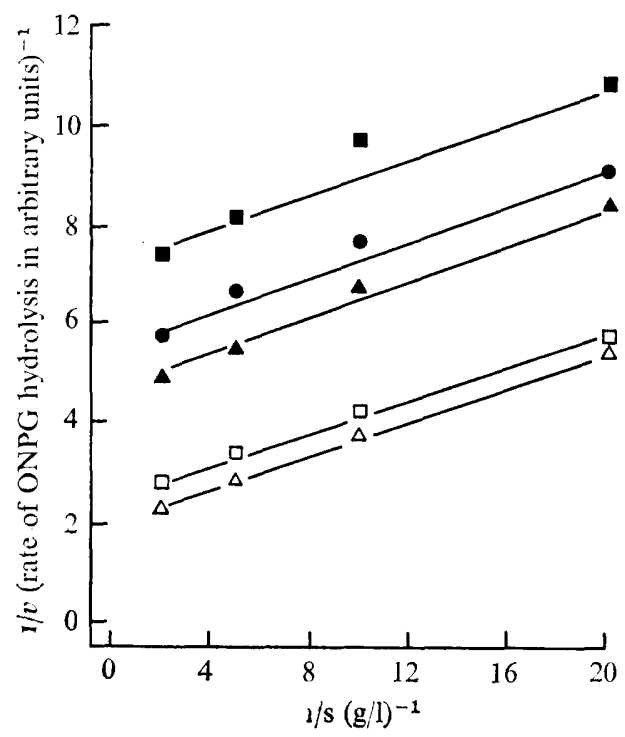

Fig. 2. Characterization of inhibitory effects of $3 \mathrm{FG}$ on $\beta$-galactosidase activity in cell-free extracts. Reaction velocity $(v)$ was determined at differing concentrations of substrate " $(s)$. ONPG was used as substrate. $3 \mathrm{FG}$ concentrations were : $25 \mathrm{~mm}(\boldsymbol{\sigma}) ; 10 \mathrm{~mm}(\boldsymbol{O}) ; 2.5 \mathrm{~mm}(\Delta) ; 1 \cdot 0 \mathrm{~mm}(\square)$ and zero $(\triangle)$.

Table 4. Inhibition of $\beta$-galactosidase activity in cell-free extracts by $3 F G$ and by glucose

$\beta$-Galactosidase activity was determined by hydrolysis of $\mathrm{I} \cdot 7 \mathrm{~mm}-\mathrm{ONPG}$.

\begin{tabular}{|c|c|c|}
\hline \multirow{2}{*}{$\begin{array}{c}3 \mathrm{FG} \text { or } \\
\text { glucose }(\mathrm{mm})\end{array}$} & \multicolumn{2}{|c|}{$\begin{array}{c}\text { Inhibition of } \\
\beta \text {-galactosidase activity }(\%)\end{array}$} \\
\hline & By $3 F G$ & By glucose \\
\hline 50 & 74 & 36 \\
\hline 25 & 67 & 29 \\
\hline IO & 56 & 20 \\
\hline $2 \cdot 5$ & 37 & 5 \\
\hline$I \cdot 0$ & 17 & 0 \\
\hline $0 \cdot I$ & 3 & - \\
\hline
\end{tabular}

cellular inducer concentration which might result from a decreased rate of lactose transport and metabolism.

Table 5 shows the effect on growth and $\beta$-galactosidase synthesis of adding $3 \mathrm{FG}$ and combinations of cyclic AMP and IPTG to bacteria growing exponentially in lactose medium. The addition of $3 \mathrm{FG}$ alone prevented further $\beta$-galactosidase synthesis, and growth continued for less than two generations. IPTG did not overcome either of these effects, so evidently any lowering of the intracellular inducer concentration is not significant in this system. Cyclic AMP ( $5 \mathrm{mM}$ ), however, restored the differential rate of $\beta$-galactosidase synthesis in the presence of ${ }_{3} \mathrm{FG}$ to that observed in its absence, and allowed growth in the presence of ${ }_{3} \mathrm{FG}$ at a constant but lowered growth rate. This indicates that repression of $\beta$-galactosidase and galactoside permease synthesis is a significant factor in $3 \mathrm{FG}$ inhibition of growth with lactose. However, $3 \mathrm{FG}$ in the presence of cyclic AMP still caused a $70 \%$ 
Table 5. Effects of cAMP and IPTG on the differential rate of $\beta$-galactosidase synthesis and on the growth of Escherichia coli in lactose medium with Io $m M-3 F G$

A culture growing exponentially in lactose medium was divided into five parts and the additions below were made. Growth and $\beta$-galactosidase synthesis were then followed over several generations except where $3 \mathrm{FG}$ or $3 \mathrm{FG}$ plus IPTG were added, when growth continued for only $\mathrm{I} \cdot 5$ generations.

\begin{tabular}{|c|c|c|}
\hline $\begin{array}{l}\text { Additions to } \\
\text { lactose medium }\end{array}$ & Growth rate $\left(\mathrm{h}^{-1}\right)$ & $\begin{array}{l}\text { synthesis* } \\
\text { (arbitrary units) }\end{array}$ \\
\hline $\begin{array}{l}\text { None } \\
\text { 3FG }\end{array}$ & $\begin{array}{l}0.63 \\
\text { Fell to zero }\end{array}$ & $\begin{array}{l}0.90 \\
(0.02)\end{array}$ \\
\hline 3FG: I 0 mM-IPTG & Fell to zero & $(0.03)$ \\
\hline 3FG:5 mM-cyclic AMP & 0.20 & I 04 \\
\hline $\left.\begin{array}{l}\text { 3FG:1.0 mM-IPTG: } \\
5 \text { mM-cyclic AMP }\end{array}\right\}$ & 0.50 & $2 \cdot 13$ \\
\hline
\end{tabular}

decrease in growth rate, and this was presumably due to effects on $\beta$-galactosidase and galactoside permease activity. This conclusion is supported by the observation that, in the presence of ${ }_{3} \mathrm{FG}$, IPTG and cyclic AMP, the differential rate of $\beta$-galactosidase synthesis by organisms growing in lactose medium was $2 \cdot 3$ times greater than that of control cultures with none of these additions, and the growth rate was $80 \%$ of the control. The effect of $3 \mathrm{FG}$ on the growth of Escherichia coli with lactose was therefore almost completely overcome in conditions where there was specifically a high level of $\beta$-galactosidase and galactoside permease. The activity of one or both of these enzymes must then limit growth with lactose in the presence of $3 \mathrm{FG}$ under normal conditions.

While 3 FG inhibits the activity and synthesis of both $\beta$-galactosidase and galactoside permease, it seems possible that growth with lactose in the presence of ${ }_{3} \mathrm{FG}$ is limited only by the synthesis and activity of the galactoside permease. $\beta$-Galactosidase activity in Escherichia coli seems to exceed galactoside transport activity greatly, since viable organisms hydrolysed ONPG at I/2oth the rate of toluenized bacteria. The relatively small inhibition of $\beta$-galactosidase activity caused by $3 \mathrm{FG}$ would therefore appear to be insignificant.

It is possible to conclude, therefore, that $3 \mathrm{FG}$, when added to organisms growing exponentially in lactose medium, initially lowers the growth rate approximately $70 \%$ by inhibiting lactose transport; lactose transport then limits growth rate, and the growth rate decreases further as synthesis of galactosidase permease is halted. This conclusion may be tested by constructing theoretical curves to represent growth of lactose cultures after addition of $3 \mathrm{FG}$. Three theoretical curves, based on different assumptions concerning the mechanism of $3 \mathrm{FG}$ action, are compared in Fig. 3 with the curve obtained in practice. The theoretical curve $(e)$ which is based on the conclusion reached above agrees closely with the curve obtained in practice $(b)$. In constructing theoretical curves no account was taken of maintenance energy (Pirt, 1965). The maintenance energy becomes more significant at low growth rates, and this may explain the eventual cessation of growth in the presence of $3 \mathrm{FG}$ (curve $b$ ), whereas in the theoretical curve $(e)$ growth continues.

\section{Mutants resistant to inhibitory growth effects of $3 F G$}

The increase in lag which $3 \mathrm{FG}$ may cause when glucose-grown organisms are transferred to media containing other carbon sources may express either the time required for the popu- 


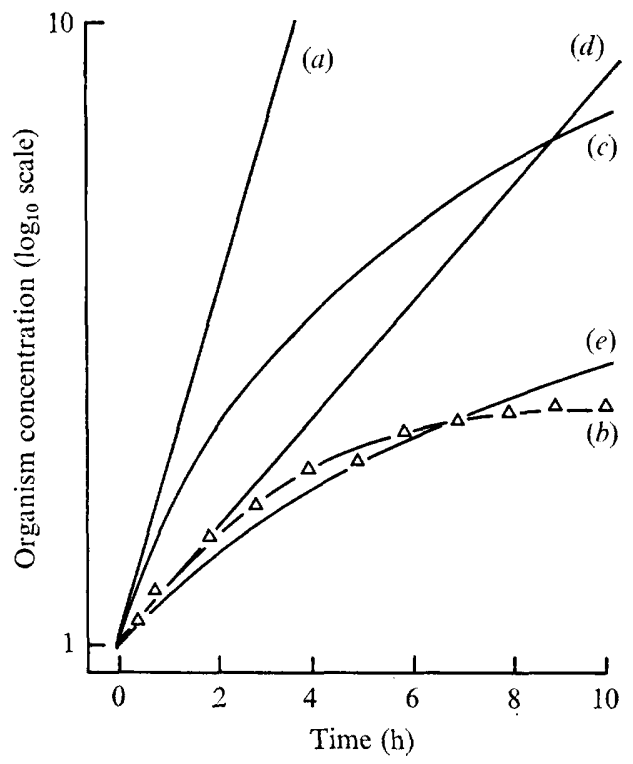

Fig. 3. The effect of adding $3 \mathrm{FG}$ to Escherichia coli growing exponentially in lactose medium. Curve $(a)$ represents exponential growth in lactose medium with a specific growth rate $(\mu)$ of $0.63 \mathrm{~h}^{-1}$; this growth rate is the maximum for the conditions used. Curve $(b)$ represents the effect of adding ${ }_{3} \mathrm{FG}$ to $10 \mathrm{~mm}$ at zero time. Curve $(c)$ is based on the assumption that, after addition of $3 \mathrm{FG}$, lactose permeation immediately begins to limit growth because synthesis of galactoside permease ceases: the growth rate falls with the specific activity of galactoside permease. If the bacteria are growing exponentially at $\mu_{\max }$ and their concentration is $x_{0}$ when $3 \mathrm{FG}$ is added, then, by the time organism concentration has risen to $\left(x_{0}+x^{\prime}\right)$ growth rate will have fallen to

$$
\frac{x_{0}}{x_{0}+x^{\prime}} \mu_{\max }
$$

Since $\mu=1 / x . \mathrm{d} x / \mathrm{d} t$ where $t$ is time, growth in this particular case is given by:

$$
\begin{gathered}
\mathrm{d} x=x_{0} \mu_{\max } \mathrm{d} t \\
\int_{x_{0}}^{x} \mathrm{~d} x=x_{0} \mu_{\max } \int_{0}^{t} \mathrm{~d} t
\end{gathered}
$$

hence $x=x_{0}\left(\mathrm{I}+\mu_{\max } t\right)$.

Curve $(d)$ is based on the assumption that, after the addition of ${ }_{3} \mathrm{FG}, \mu$ falls by $70 \%$ due to inhibition of galactoside permease activity, to $0.3 \mu_{\max }$.

Curve $(e)$ is based on the assumption that, after the addition of $3 \mathrm{FG}$, growth is affected by both factors given in $(c)$ and $(d)$, so that growth is given by

i.e. $x=x_{0}\left(\mathrm{I}+0 \cdot 3 \mu_{\max } t\right)$.

$$
\mathrm{d} x=x_{0} \cdot 0 \cdot 3 \mu_{\max } \mathrm{d} t
$$

lation as a whole to adapt to ${ }_{3} \mathrm{FG}$ or the time required to select a ${ }_{3} \mathrm{FG}$-resistant mutant population. Glucose-grown organisms were plated out on lactose agar with and without Io mM-3FG. Colonies appeared on the lactose-3FG plates at a frequency of $3 \times \mathrm{IO}^{-6}$ that at which they appeared on lactose plates. Sixty colonies from lactose-3FG plates were able to grow in lactose medium at the same rate as the wild-type, but growth rates in glucose medium were reduced from $0.60 \mathrm{~h}^{-1}$ for the wild-type to 0.20 to $0.43 \mathrm{~h}^{-1}$ for the mutants.

Five mutants whose growth rates in glucose medium were $0.20,0.24,0.27,0.34$ and $0.43 \mathrm{~h}^{-1}$ grew at the wild-type growth rate with fructose, glycerol, pyruvate, acetate and succinate in addition to lactose. Since the growth rate of the mutants with all these carbon 
sources was unaffected, the lowered growth rate in glucose medium suggests that the mutation(s) involved steps early in glucose metabolism. Both the transport and initial phosphorylation of glucose in Escherichia coli are mediated by the phosphoenolpyruvate-dependent phosphotransferase system originally described by Kundig et al. (I964). In the wild-type organism, $3 \mathrm{FG}$ is a substrate for this system. The rate of phosphorylation of $3 \mathrm{FG}$ in frozen and thawed 3 FG-resistant mutants was similarly determined and found to be between 5 and $15 \%$ of the rate for the wild-type (Table $\mathrm{I}$ ). This, together with the results from growth studies, indicates that resistance to $3 \mathrm{FG}$ in the mutants was due to a mutation in the phosphoenolpyruvate-dependent phosphotransferase system which diminished the ability of the system to phosphorylate and presumably transport $3 \mathrm{FG}$.

The phosphoenolpyruvate-dependent phosphotransferase system consists of three proteins, HPr, Enzyme I and Enzyme II, which participate in the following reactions:

$$
\begin{gathered}
\text { Phosphoenolpyruvate }+\operatorname{HPr} \underset{\mathrm{Mg}^{2+}}{\stackrel{\text { Enzyme I }}{\longrightarrow}} \text { phospho-HPr }+ \text { pyruvate } \\
\text { Phospho-HPr }+ \text { sugar } \underset{\mathrm{Mg}^{2+}}{\stackrel{\text { Enzyme II }}{\longrightarrow}} \text { sugar-phosphate }+\mathrm{HPr}
\end{gathered}
$$

HPr is a small protein which functions as a phosphoryl carrier, and Enzyme II is one of a number of enzymes which differ in their specificities for sugars.

Mutations affecting either HPr, Enzyme I, or Enzyme II specific for glucose, might be expected to lead to lowered glucose and $3 \mathrm{FG}$ phosphorylation and transport. However, fructose transport is also mediated by the phosphoenolpyruvate-dependent phosphotransferase system in Escherichia coli (Fraenkel, 1968) and fructose was utilized normally by the 3FG-resistant mutants. This implies that Enzyme I and HPr are normal in the mutants and that, therefore, the mutants have either lost Enzyme II or possess a functionally deficient form specific for glucose and for 3 FG. Kornberg \& Smith (I972) reached a similar conclusion with regard to a 3 FG-resistant mutant isolated by its ability to grow on fructose in the presence of $3 \mathrm{FG}$, and were able to determine the genetic location of the mutation.

Although the five mutants analysed in greater detail were isolated by their ability to grow on lactose-3FG agar they were generally resistant to the inhibitory effects of $3 \mathrm{FG}$ on the utilization of other carbon sources. $3 \mathrm{FG}$ ( $\mathrm{I} \mathrm{mM}$ ) caused only a 5 to $20 \%$ decrease in growth rate with lactose, fructose or succinate as carbon source. The utilization of glycerol was more susceptible to inhibition by $3 \mathrm{FG}$, and in four of the mutants $\mathrm{I}$ mM-3FG lowered the growth rate in glycerol medium by $80 \%$; the growth rate of the remaining mutant (which grew in glucose medium at $0.34 \mathrm{~h}^{-1}$ ) was inhibited by only $20 \%$.

With regard to lactose utilization by the mutants, Io mM-3FG did not affect the differential rate of $\beta$-galactosidase synthesis in organisms growing exponentially in lactose medium, though it still caused a transient repression of $\beta$-galactosidase synthesis and inhibited ONPG transport in resting bacteria. Ten $\mathrm{mM}_{-3} \mathrm{FG}$ inhibited ONPG transport by between 40 and $50 \%$, and during the first $30 \mathrm{~min}$ after addition of IPTG to organisms growing with succinate repressed $\beta$-galactosidase synthesis by 50 to $65 \%$. In the wild-type, the corresponding levels of inhibition were 80 and $90 \%$ respectively.

While all the ${ }_{3} \mathrm{FG}$-resistant mutants isolated in this investigation were of the same type, a second type of mutation was also found to confer some resistance to 3 FG. Escherichia coli ML308, a mutant of $E$. coli $\mathrm{KI} 2$ in which production of $\beta$-galactosidase and galactoside permease is constitutive, grew in lactose medium containing Io mM-3FG. Its growth rate, however, was only $\mathrm{I} 6 \%$ of that without $3 \mathrm{FG}$, and $3 \mathrm{FG}$ lowered the differential rate of 
$\beta$-galactosidase synthesis by $50 \%$. The ability of this mutant to grow in lactose-3FG medium is a further indication that $3 \mathrm{FG}$ affects growth with lactose, at least in part, by repression of $\beta$-galactosidase and galactoside permease synthesis.

\section{DISCUSSION}

While 3 FG has no effect on the growth of Escherichia coli with glucose, it may severely affect the utilization of other carbon sources. This is apparently due to inhibition by $3 \mathrm{FG}$ of specific steps involved in the utilization of these other carbon sources, steps which are not involved in glucose utilization. In causing this type of inhibition, $3 \mathrm{FG}$ is presumably acting as an analogue of glucose, and the reactions which it brings about are those which ensure the preferential utilization of glucose over other carbon sources. Such inhibitory reactions are often attributed to catabolites, but the ability of ${ }_{3} \mathrm{FG}$ to bring them about indicates that they are due to ${ }_{3} \mathrm{FG}$ itself, to the sugar phosphate or to some other closely related metabolic product.

With regard to inhibition of lactose utilization by $3 \mathrm{FG}$, both catabolite repression (Magasanik, I96I) and catabolite inhibition (McGinnis \& Paigen, 1969) seem important. Glucose and glucose analogues cause a transient repression of $\beta$-galactosidase synthesis (Tyler, Loomis \& Magasanik, 1967) though, while glucose may cause a more permanent catabolite repression (Magasanik, I96I), non-catabolizable glucose analogues have not been reported to do so. Evidence that $3 \mathrm{FG}$ may cause catabolite repression is mainly indirect and based on the ability of cyclic AMP to overcome the long term repressive effect of 3 FG on the utilization of lactose, though 3 FG does have a permanent repressive effect on $\beta$ galactosidase synthesis in organisms growing with pyruvate. Evidence that catabolite repression may be due to compounds which are not catabolites of glucose has been presented by Goldenbaum, Broman \& Dobrogosz (1970), who showed that acetylglucosamine caused catabolite repression of $\beta$-galactosidase synthesis in a mutant of Escherichia coli able to phosphorylate acetylglucosamine but not metabolize it further.

The effect of ${ }_{3} \mathrm{FG}$ on galactoside transport, and upon TMG efflux from resting bacteria is similar to that reported for other glucose analogues (Winkler \& Wilson, 1967). However, in organisms growing in lactose medium, $3 \mathrm{FG}$ also appears to inhibit galactoside transport to the extent of limiting the growth rate, in contrast to the effect of $\alpha$-methylglucoside which, with the strain and conditions used in this investigation, caused only a transient lowering of the growth rate. McGinnis \& Paigen (1969) showed that in Escherichia coli growing in lactose medium, glucose inhibited galactoside permease and/or $\beta$-galactosidase. ${ }_{3} \mathrm{FG}$ inhibition indicates that the permease inhibition is the more significant.

Inhibition of galactoside transport may also lead to inhibition of $\beta$-galactosidase and galactoside permease synthesis by lowering the intracellular inducer concentration (Cohn \& Horibata, 1959). Inhibition of inducer uptake is another important mechanism in the prevention of galactose utilization by glucose (Adhya \& Echols, I 966; Lengeler, I966) and, as McGinnis \& Paigen (I969) suggested, may be generally important. It would not, however, appear to be an important mechanism in $3 \mathrm{FG}$ inhibition of growth on lactose since, firstly, a high concentration of IPTG did not overcome the inhibition, and, secondly, with lactose, $3 \mathrm{FG}$ and cAMP together there was sufficient intracellular inducer to allow a high rate of $\beta$-galactosidase synthesis (Table 5).

The mutants able to grow on lactose-3FG agar all appear to have a deficiency in $3 \mathrm{FG}$ transport. $3 \mathrm{FG}$ was phosphorylated at a decreased rate by the phosphoenolpyruvatedependent phosphotransferase system in frozen and thawed mutant cells, and the mutants 
grew in glucose medium at a lowered rate and were still susceptible to some inhibitory growth effects of ${ }_{3} \mathrm{FG}$. Thus ${ }_{3} \mathrm{FG}$ uptake in the mutants is lowered rather than abolished. The severity of the effect of $3 \mathrm{FG}$ on glycerol utilization in four out of five of the mutants presumably reflected a small uptake of $3 \mathrm{FG}$ and the susceptibility of glycerol permease, $\mathrm{L}-\alpha$-glycerophosphate dehydrogenase and glycerol kinase (all of which are inducible and involved in glycerol utilization) to repression by $3 \mathrm{FG}$. The frequency with which ${ }_{3} \mathrm{FG}$ transport-deficient mutants were isolated from glucose-grown organisms transferred to a lactose-3FG medium was sufficiently high to suggest that, whenever $3 \mathrm{FG}$ increased lags by more than twenty generation times, eventual growth was due to selection of these mutants.

It is noteworthy that $3 \mathrm{FG}$ is able to cause effects analogous to those of glucose, which 2-deoxyglucose and $\alpha$-methylglucoside and other glucose analogues are unable or only partially able to do.

We wish to thank the Wellcome Laboratories for financial support, and Dr A. K. Palmer, for synthesizing the $3 \mathrm{FG}$ used in this investigation.

\section{REFERENCES}

ADHYA, S. \& Echols, M. (1966). Glucose effect and the galactose enzymes of Escherichia coli: Correlation between glucose inhibition of induction and inducer transport. Journal of Bacteriology 92, 60I-608.

Brunt, R. V. \& TAYLOR, N. F. (1967). The metabolism of 3-deoxy-3-fluoro-D-glucose by Saccharomyces cerevisiae. Biochemical Journal ro5, $4 \mathrm{I}-43 \mathrm{C}$.

Buck, K. W., Foster, A. B., Hems, R. \& Webber, J. M. (I966). A new route to 3-deoxy-3-fluoro-D-glucose. Carbohydrate Research 3, 137-138.

Cohn, M. \& Horibata, K. (I959). Inhibition by glucose of the induced synthesis of the $\beta$-galactosidase enzyme system of Escherichia coli. Analysis of maintenance. Journal of Bacteriology 78, 60I-6r 2.

Dixon, M. \& Webb, E. C. (1964). Enzymes, 2nd edn. New York: Academic Press.

Dubois, M., Gilles, K. A., Hamilton, J. K., Rebers, P. A. \& Smith, F. (I956). Colorimetric method for determination of sugars and related substances. Analytical Chemistry 28, 350-356.

Foster, A. B., Hems, R. \& Webber, J. M. (1967). Fluorinated carbohydrates. Part I. 3-deoxy-3-fluoro-Dglucose. Carbohydrate Research 5, 292-30I.

Fraenkel, D. G. (I968). The phosphoenolpyruvate-initiated pathway of fructose metabolism in Escherichia coli. Journal of Biological Chemistry 243, 6458-6463.

Grosh, S. \& Grosh, D. (1 968). Probable role of a membrane bound phosphoenolpyruvate-hexose phosphotransferase system of Escherichia coli in the permeation of sugars. Indian Journal of Biochemistry $\mathbf{5}$, 49-52.

Goldenbaum, P. E., Broman, R. L. \& Dobrogosz, W. J. (I970). Cyclic 3' 3' $^{\prime}$-adenosine monophosphate and $\mathrm{N}$-acetylglucosamine-6-phosphate as regulatory signals in catabolite repression of the lac operon in Escherichia coli. Journal of Bacteriology 103, 663-670.

Hough, L. \& Jones, J. K. N. (1962). Chromatography on paper. In Methods in Carbohydrate Chemistry, vol. I, pp. 21-30. Edited by R. L. Whistler and M. L. Wolfrom. New York: Academic Press.

Hugget, A. St. G. \& Nixon, D. A. (1957). Enzymic determination of blood glucose. Biochemical Journal 66, $12 \mathrm{p}$.

JACOB, F. \& MONOD, J. (196I). On the regulation of gene activity. Cold Spring Harbor Symposium on Quantitative Biology 26, 195-2I I.

KornberG, H. L. \& SMITH, J. (I972). Genetic control of glucose uptake by Escherichia coli. FEBS Letters 20, $270-272$.

Kundig, W., GHosh, S. \& Roseman, S. (1964). Phosphate bound to histidine in a protein as an intermediate in a novel phosphotransferase system. Proceedings of the National Academy of Sciences of the United States of America 52, 1067-1074.

LEDERBERG, J. (1950). The $\beta$-D-galactosidase of Escherichia coli KI 2. Journal of Bacteriology 60, 38I-392.

LENGELER, J. (1966). Untersuchungen zum Glukose-Effekt bei der Synthese der Galaktose-Enzyme von Escherichia coli. Zeitschrift für Vererbungslehre 98, 203-229. 
MCGinnis, J. F. \& PAigen, K. (1969). Catabolite inhibition: a general phenomenon in the control of carbohydrate utilisation. Journal of Bacteriology 100, 902-913.

MagasaniK, B. (196I). Catabolite repression. Cold Spring Harbor Symposium on Quantitative Biology 26, $249-256$.

MiLEs, R. J. (1972). The effect of 3-deoxy-3-fluoro-D-glucose on some micro-organisms. Ph.D. Thesis, University of London.

Miles, R. J. \& PIRT, S. J. (I969). The effect of 3-deoxy-3-fluoro-D-glucose, a non-metabolisable sugar, on the metabolism of Saccharomyces cerevisiae. Biochemical Journal r14, Iop.

Miles, R. J. \& PIRT, S. J. (1972). Inhibition of the utilisation of lactose and other carbon sources by 3-deoxy-3-fluoro-D-glucose in Escherichia coli. Biochemical Journal 127, 6op.

Palmer, A. K. (197I). Some fluoro-carbohydrates. Ph.D. Thesis, University of London.

Pazur, J. H. (1966). Glucose oxidase from Aspergillus niger. In Methods in Enzymology, vol. 9, pp. 82-87. Edited by S. P. Colowick and N. O. Kaplan. New York: Academic Press.

Perlman, R. L., de Crombrugghe, B. \& Pastan, I. (1969). Cyclic AMP regulates catabolite and transient repression in Escherichia coli. Nature, London 223, 810-81 2.

PIRT, S. J. (1965). The maintenance energy of bacteria in growing cultures. Proceedings of the Royal Society of London B r63, 224-23I.

Rickenberg, H. V., Cohen, G. N., Buttin, G. \& Monod, J. (1956). La galactoside-perméase d'Escherichia coli. Annales de l'Institut Pasteur de Lille 9r, 829-857.

Tyler, B., LoOmis, W. F. \& MAgasaniK, B. (1967). Transient repression of the lac operon. Journal of Bacteriology 94, 200I-20II.

White, F. H. \& TAYLOR, N. F. (I970). Metabolism of 3-deoxy-3-fluoro-D-glucose by Pseudomonas fluorescens. FEBS Letters II, 268-270.

WinkLeR, H. H. \& WiLSON, T. M. (I966). The role of energy coupling in the transport of $\beta$-galactosides in Escherichia coli. Journal of Biological Chemistry 24I, 2200-22 I I.

WINKLER, H. H. \& WILSON, T. M. (I967). Inhibition of $\beta$-galactoside transport by substrates of the glucose transport system in Escherichia coli. Biochimica et biophysica acta 135, I030-I05I.

Woodward, B., Taylor, N. F. \& BrunT, R. V. (I969). Effect of 3-deoxy-3-fluoro-D-glucose on Saccharomyces cerevisiae. Biochemical Journal II4, 445-447.

Woodward, B., TaYlor, N. F. \& BrUnt, R. V. (I97I). Effect of 3-deoxy-3-fluoro-D-glucose on glycolytic intermediates and adenine nucleotides in resting cells of Saccharomyces cerevisiae. Biochemical Pharmacology 20, 1071-1077. 